\title{
A review on gut microbiota: a central factor in the pathophysiology of obesity
}

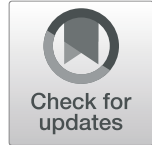

\author{
A. L. Cunningham ${ }^{1,2^{*}}$ D, J. W. Stephens ${ }^{2}$ and D. A. Harris ${ }^{1,2}$
}

\begin{abstract}
Obesity and its complications constitute a substantial burden. Considerable published research describes the novel relationships between obesity and gut microbiota communities. It is becoming evident that microbiota behave in a pivotal role in their ability to influence homeostatic mechanisms either to the benefit or detriment of host health, the extent of which is not fully understood. A greater understanding of the contribution of gut microbiota towards host pathophysiology is revealing new therapeutic avenues to tackle the global obesity epidemic. This review focuses on causal relationships and associations with obesity, proposed central mechanisms encouraging the development of obesity and promising prospective methods for microbiota manipulation.
\end{abstract}

Keywords: Gut microbiota, Obesity, Metabolic syndrome, Faecal microbiota transplant

\section{Background}

The worldwide prevalence of obesity has approximately tripled since 1975 with a current estimate of 1.9 billion adults being classed as overweight (body mass index, BMI $\geq 25 \mathrm{~kg} / \mathrm{m}^{2}$ ). This currently outnumbers those with malnutrition $[1,2]$. Obesity is defined as the 'abnormal or excessive fat accumulation that may impair health' and is measured using the BMI [3]. Factors contributing towards the obesity epidemic include an increased accessibility to energy-dense foods, an increase in sedentary activity and the possible involvement of the gut microbiota on host metabolism.

Although the fundamental cause of obesity is an energy imbalance between the calories consumed and the calories expended [1], body weight is not influenced by the calorific ingestion, but rather by the calories that are absorbed [4]. When adipose tissue exceeds its buffering capacity to store excess triglycerides, a resulting overflow of lipids into the systemic circulation occurs [5]. This lipid overspill to non-adipose tissues such as the liver,

\footnotetext{
* Correspondence: cunninghamal@doctors.org.uk

${ }^{1}$ Department of Surgery, Swansea Bay University Health Board, Swansea SA2 8QA, UK

${ }^{2}$ Swansea University Medical School, Swansea University, Swansea SA2 8QA, UK
}

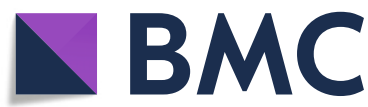

(c) The Author(s). 2021 Open Access This article is licensed under a Creative Commons Attribution 4.0 International License, which permits use, sharing, adaptation, distribution and reproduction in any medium or format, as long as you give appropriate credit to the original author(s) and the source, provide a link to the Creative Commons licence, and indicate if changes were made. The images or other third party material in this article are included in the article's Creative Commons licence, unless indicated otherwise in a credit line to the material. If material is not included in the article's Creative Commons licence and your intended use is not permitted by statutory regulation or exceeds the permitted use, you will need to obtain permission directly from the copyright holder. To view a copy of this licence, visit http://creativecommons.org/licenses/by/4.0/ The Creative Commons Public Domain Dedication waiver (http://creativecommons.org/publicdomain/zero/1.0/) applies to the data made available in this article, unless otherwise stated in a credit line to the data.

\section{Gut microbiota}

In the early 1900s, Élie Metchnikoff, a Russian-born zoologist and microbiologist first postulated the theory that gut microbiota behave as central modulators influencing host homeostasis and metabolism [6]. He believed that disruption of host homeostasis by particular bacteria increased the possibility of a disease state resulting in systemic toxicity from bacterial by-products [6] An adult human is colonised by approximately 100 trillion microbes, most of which are predominantly found in the gastrointestinal tract (GIT), the largest population residing in the colon [7].

Scientists are gaining a greater understanding of the 'normal' bacterial communities and physiology of present gut microbiota through population research such as the Human Microbiome Project [8].

skeletal muscle and pancreas culminates in ectopic fat storage and the subsequent development of insulin resistance. Secondly, inflammation in adipose tissue increases, triggering the production and secretion of pro-inflammatory cytokines and adipokines, which conance and altered glucose homeostasis [5]. 
Taxonomy is the study of classifying microbiota and provides a rigid structure for the arrangement of particular microbiota into groups on the basis of mutual similarity or evolutionary relatedness. In bacterial taxonomy the most commonly used ranks (levels) in ascending order are species, genera, families, orders, classes, phyla and domain [9].

The most abundant faecal bacterial groups of both lean and obese subjects are the phyla Firmicutes and Bacteroidetes [10, 11]. Approximately $90 \%$ of all phylotypes of gut bacteria belong to either the grampositive Firmicutes (64\%) or the gram-negative Bacteroidetes $(23 \%)$ [8, 12]. Other important phyla are Proteobacteria, Actinobacteria, Verrucomicrobia and Fusobacteria [8, 13-15]. The host genome is pivotal in controlling the composition of gut microbiota, however many external factors such as diet, illness, lifestyle, hygiene and the use of medications can contribute to changes in bacterial communities [16-18]. Growing evidence illustrates that dietary modification may be extremely influential in accounting for gut microbiota variations $[17,19,20]$ (summarised in Fig. 1).

\section{Microbiota population differences in obesity}

Maintaining the heterogeneity and stability within the gut microbiota community is essential for promoting host health. Alterations in diversity and microbiota community structure may affect host metabolism resulting in obesity. Subjects with obesity have consistently demonstrated a reduction in diversity and richness in microbial populations which can be reversed using weight loss interventions (diet low in fat and animal products, rich in fruit and vegetables) [21, 22]. Microbial diversity has been linked to the metabolic function of gut microbiota and low bacterial richness has been suggested to be a risk factor for obesity and low-grade inflammation [23, 24].

Obesity-related host microbiome display enrichment in particular gene categories involved in carbohydrate and lipid metabolism, and enzymes involved in glucose and insulin signaling pathways are downregulated [11, 21, 25]. Le Chatelier et al., analysed gene counts of a large cohort of obese and healthy subjects. Subjects identified with a low gene count (LGC) showed traits typical of an 'obese phenotype' associated with greater overall adiposity, insulin resistance and dyslipidaemia [26]. LGC subjects also had increased levels of serum leptin, triglycerides and free-fatty acids, high density lipoprotein-cholesterol, decreased serum adiponectin and an elevated inflammatory phenotype [26, 27]. Dietary restriction among overweight or obese patients is less efficient in LGC than in high gene count individuals when targeting the improvement of insulin sensitivity and lowering of lipid and inflammatory biomarkers $[26,28]$.

The inconsistency across both animal and human studies regarding the Firmicutes/Bacteroidetes phyla ratio in obesity diminishes the significance of this particular finding. This review will therefore focus on more indepth microbiota relationship findings below phylum level as summarised in Table 1.

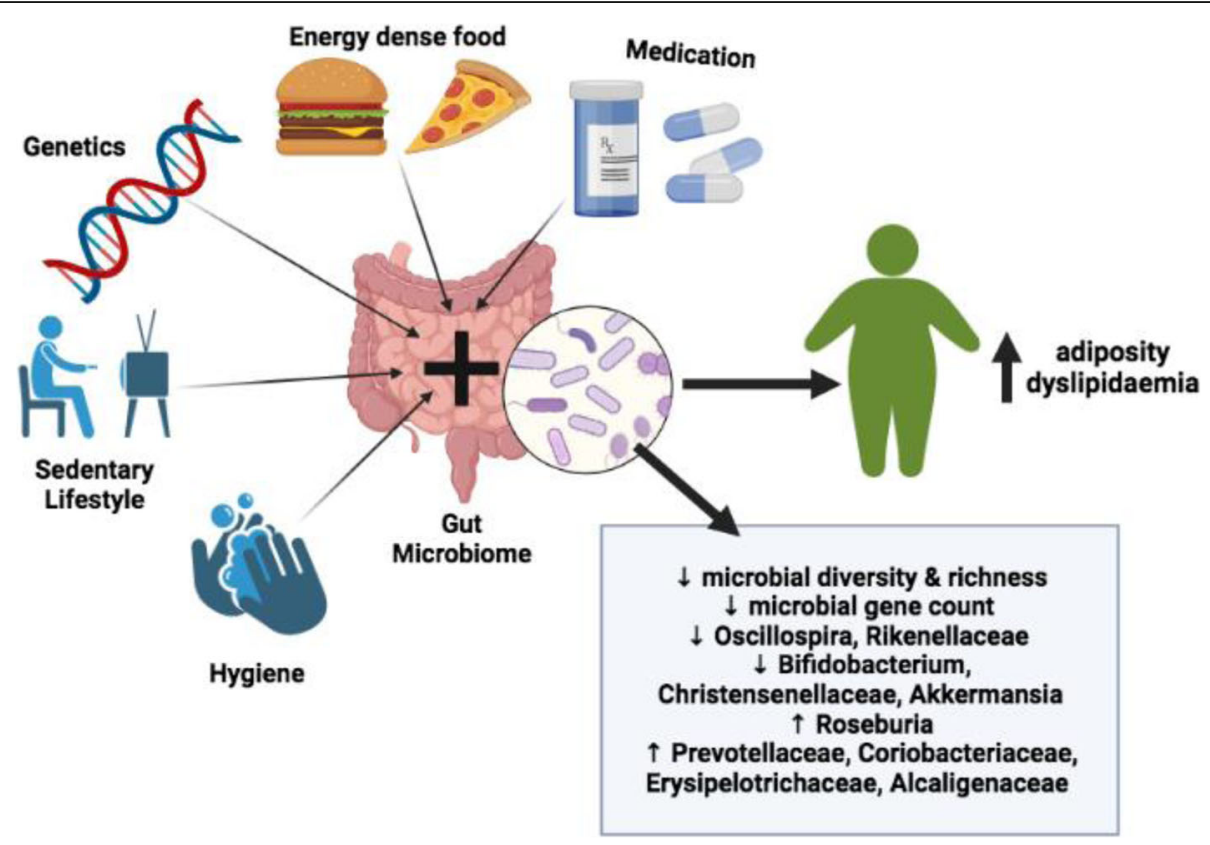

Fig. 1 Contributions towards obesity development including gut microbiota findings 
Table 1 Gut microbiota differences in obese human and rodent cohorts, preoperative bariatric dietary cohort, post-bariatric surgery human and rodent cohorts, post-allogenic FMT cohort

\begin{tabular}{|c|c|}
\hline Cohort & Microbiota Findings \\
\hline Obese cohort [10, 11, 22, 29-32] & $\begin{array}{l}\downarrow \text { Rikenellaceae and Christensenellaceae } \\
\downarrow \text { Bifidobacterium, Oscillospira and Akkermansia }\end{array}$ \\
\hline Obese cohort [33] & $\downarrow$ Alistipes finegoldii and Alistipes senegalensis \\
\hline Obese cohort [34] & Alistipes $=$ marker of persistent weight loss success \\
\hline Obese cohort $[11,35]$ & $\downarrow$ Faecali prausnitzii \\
\hline Obese cohort $[21,32,36]$ & Weight loss $\uparrow$ Faecali prausnitzii, Akkermansia and Christensenellaceae \\
\hline Obese cohort [37] & $\uparrow$ Prevotellaceae, Coriobacteriaceae, Erysipelotrichaceae, and Alcaligenaceae \\
\hline Elevated BMI $[38,39]$ & $\uparrow$ Roseburia \\
\hline Obese cohort [40] & $\uparrow$ Eubacterium dolichum \\
\hline Obese cohort [37] & $\uparrow \mathrm{H}_{2}$-producing bacteria; (Prevotellaceae, certain groups within the Firmicutes and Archaea) \\
\hline Obese cohort $[11,26]$ & $\begin{array}{l}\uparrow \text { gram-negative microbes } \\
\uparrow \text { Fusobacterium, Escherichia-Shigella, Pseudomonas and Campylobacter }\end{array}$ \\
\hline Obese children and overweight women $[30,41]$ & $\uparrow$ Staphylococcus aureus \\
\hline Obese cohort on preoperative diet [42] & $\begin{array}{l}\downarrow \text { Streptococcaceae and Ruminococcaceae } \\
\uparrow \text { Rikenellaceae and Bifidobacteriaceae }\end{array}$ \\
\hline Post-bariatric surgery $[37,42,43]$ & $\begin{array}{l}\uparrow \text { Gammaproteobacteria (Enterobacteriaceae) } \\
\downarrow \text { Firmicutes (Clostridium difficile, Clostridium hiranonis, and Gemella sanguinis) } \\
\downarrow \text { methanogens }\end{array}$ \\
\hline Post-bariatric surgery $[43,44]$ & $\uparrow$ Escherichia, Klebsiella, and Pseudomonas \\
\hline Six months post-bariatric surgery [42] & $\begin{array}{l}\uparrow \text { Streptococcaceae and Veillonellaceae } \\
\downarrow \text { Bifidobacteriaceae }\end{array}$ \\
\hline Rodent model - post bariatric surgery [45] & $\begin{array}{l}\uparrow \text { Bacteroidetes, Verrucomicrobia, and Proteobacteria } \\
\uparrow \text { Alistipes, Akkermansia, and Escherichia }\end{array}$ \\
\hline Rodent model - post bariatric surgery [46] & $\begin{array}{l}\uparrow \text { Proteobacteria (Enterobacter hormaechei) } \\
\downarrow \text { Firmicutes and Bacteroidetes }\end{array}$ \\
\hline Allogenic FMT recipients [47] & $\uparrow$ Roseburia intestinalis \\
\hline
\end{tabular}

A specific microbial signature associated with a diagnosis of obesity has still not been identified. The most common gut microbiota composition finding is a reduction in the butyrate-producing microbes together with an increase in opportunistic pathogens [29]. Consistent microbiota findings have displayed reductions in the abundances of the families Rikenellaceae and Christensenellaceae as well as a decrease in the abundance of the genera Bifidobacterium, Oscillospira and Akkermansia [10, 11, 22, 29-32].

Many of these depleted microbiota provide beneficial attributes to the host. Bifidobacterium is associated with elevated short chain fatty acids (SCFAs), decreased luminal lipopolysaccharide (LPS) and improved intestinal barrier function [31, 48]. The importance of these mechanisms are discussed in individual sections later in the review. Both Christensenellaceae and Akkermansia correlate with lower visceral fat mass, a type of fat that is considered to be an adverse cardiometabolic risk factor when in excess [24, 49]. Akkermansia is a mucindegrading microbe inhabiting the outer mucus layer of the intestinal barrier and is associated with a healthier metabolic status in obese humans [24]. It has been reported that having increased amounts of Akkermansia in the gut prior to embarking on a weight loss programme leads to greater improvements in glucose homoeostasis, blood lipids and body composition [24].

In addition to the above findings, two species within the Rikenellaceae family have been identified that correlate negatively with BMI: Alistipes finegoldii and Alistipes senegalensis [33]. This finding has been replicated in a German weight-loss intervention study who enrolled female participants on a very low calorie diet and found that the genus Alistipes was a marker of persistent weight-loss success [34]. The species Faecali prausnitzii is also significantly reduced in obesity, particularly in those patients with diabetes $[11,35]$. Weight loss in obese adults has been shown to have the reverse effects on microbiota composition and enhances the relative abundances of Faecali prausnitzii, Akkermansia and Christensenellaceae [22, 32, 36].. Faecali prausnitzii is an important butyrate-producing microbe and is understood to provide host protection against bacterial translocation [50].

Specific gut microbiota have also been reported to increase in obesity: - the families Prevotellaceae, 
Coriobacteriaceae, Erysipelotrichaceae and Alcaligenaceae [37]. Secondly, increased abundance of the genus Roseburia is consistently reported in subjects with elevated BMI $[38,39]$. Roseburia has the ability to hydrolyse and ferment polysaccharides into SCFA, thereby increasing energy harvest from the diet [51]. Lastly, the species Eubacterium dolichum has been positively associated with visceral fat mass as a surrogate marker of obesity [40].

The generation of hydrogen $\left(\mathrm{H}_{2}\right)$ in the GIT provides an inhibitory effect on gut microbiota resulting in reduced fermentation [52]. $\mathrm{H}_{2}$-producing bacteria; originating mainly from the Prevotellaceae family, certain groups within the Firmicutes and $\mathrm{H}_{2}$-oxidizing methanogenic Archaea, have been found to be in significantly greater numbers in microbiota communities of obese subjects [37]. Archaea are not bacteria but comprise a separate taxonomic kingdom and are organisms consisting of a single cell without a nucleus [53]. Methanogens readily absorb $\mathrm{H}_{2}$ allowing for continued carbohydrate fermentation by $\mathrm{H}_{2}$-producing bacterial groups resulting in greater SCFA availability and an increased availability of calories [37, 54].

As discussed later in this review, gram-negative bacteria provide a ready source of LPS, increasing the likelihood of systemic host inflammation. Gram-negative bacteria including the genera Fusobacterium, Escherichia-Shigella, Pseudomonas and Campylobacter are all prevalent in obesity $[11,26]$. The family Prevotellaceae, which provides a source of bacterial LPS is significantly enriched in obese subjects [37]. Lastly, the species Staphylococcus aureus, a well-known opportunistic pathogen, was found to be in reduced quantities in children who maintain normal weight compared with children that are overweight several years later [41]. This finding was also replicated in a cohort of overweight women [30].

It is clearly demonstrated that a reduction in gut microbiome diversity occurs in obese subjects, but there are still many unanswered questions on the precise microbial population of an obese gut microbiome. Whether it is more important to focus on microbiota composition at phyla or deeper levels such as genus and species remains open to debate and if the absence, depletion or presence of particular microbiota contributes to the development of obesity.

\section{Microbiota contribute to the development of obesity}

The exact mechanisms by which 'obese microbiota' influence the development of obesity is still unfolding. Animal models have been widely utilised for the indepth analysis of the microbe-host relationship and allow for the investigative impact of microbiota interventions in the pathogenesis of obesity. In this section we explore the basic involvement of the gut microbiome in mouse models before focusing on the potential mechanisms.

Germ free (GF)-mice display attributes indicating the possibility of resistance to developing obesity induced by consuming a high-calorific diet strongly suggesting a possible causal role for gut microbiota [55]. Allowing both GF and conventional mice (C57BL/6) access to unlimited chow, it was observed that GF-mice exhibited considerably less $(42 \%)$ total body fat than conventional mice, despite ingesting a daily consumption of $29 \%$ more chow [56]. Lupp et al. [57], also analysed GF-mice and observed that this particular cohort weighed significantly less and eliminated twice as many calories in their stool compared with their conventional counterparts. Together, these findings demonstrate that GF-mice harvest less energy from their diets suggesting that the presence of the gut microbiome increases energy harvest.

To better understand the gut microbiome involvement, GF-mice (C57BL/6), were colonised with gut microbiota extracted from conventionally raised obese mice. Within fourteen days, the GF-mice had subsequently increased their total body fat content by $60 \%$ with associated insulin resistance, despite ingesting reduced amounts of chow [56]. Several possible mechanisms were proposed: - increased microbial fermentation of dietary polysaccharides that could not previously be digested; subsequent increase in intestinal absorption of both monosaccharides and SCFAs; and microbial regulation of host genes that promote deposition of lipids in adipocytes [56].

Turnbaugh et al. [58], performed microbiota transplantation into GF-mice (lean) with microbiota extracted from both obese and lean mice. All mice were allocated equal amounts of chow. Fourteen days post-procedure, the cohort who had received 'obese' microbiota had increased their total body weight compared to those who had received 'lean' microbiota who remained lean [58]. The investigators also examined the 'obese' rodent's genome and discovered significant enrichment of gene tags (GLB1: $\beta$-galactosidase, melA: $\alpha$-galactosidase, GAA: $\alpha$ glucosidase, PFKL: 6-phosphofructokinase) encoding for enzymes involved in the degradation of dietary polysaccharides that would be otherwise indigestible [58].

Ridaura et al. [59], were the first group to perform human faecal microbiota transplantation (FMT) on a cohort of GF-rodents. Gut microbiota were extracted from adult human female twin pairs discordant for obesity. Initially, all GF-rodents were considered to be of normal weight, allocated low-fat chow and co-housed. Rodents who received 'obese' FMT exhibited growth in their total body and fat mass while those who received 'lean' FMT remained lean. Stool sequencing indicated successful integration of the human donor microbiota, including the 
transfer of functions associated with the respective lean or obese microbial communities [59].

Homeostatic mechanisms influenced by gut microbiota in the development of obesity

Gut microbiota have the capability to impact host physiology both to its benefit and detriment either directly or via microbial metabolites [60, 61]. Almost $10 \%$ of all circulating metabolites in an adult human are derived from microbiota and participate in metabolic pathways [51]. We discuss the most important mechanisms involving the contribution of gut microbiota leading to the development of host obesity (summarised in Fig. 2).

\section{Short chain free fatty acids}

The production of SCFAs by microbial fermentation has been linked to reductions in body weight and adiposity [62]. SCFAs are small organic monocarboxylic acids and constitute the major microbial metabolites produced during anaerobic carbohydrate fermentation in the gut [63]. SCFAs consist of one to six carbons of which acetate $(\mathrm{C} 2)$, propionate $(\mathrm{C} 3)$ and butyrate $(\mathrm{C} 4)$ are the most abundant ( $\geq 95 \%)$ [64]. GF-mice are devoid of SCFAs, highlighting the central role of microbiota in the production of SCFAs $[65,66]$. SCFAs target host metabolic signaling pathways through coupling action with selected G-protein-coupled receptors (GPR41, GPR43, GPR119, GPR109A), which are abundant in adipocytes, gut immune cells and epithelial cells [67-70].
These receptors are not stimulated equally by all SCFAs. Propionate primarily activates GPR41, butyrate activates GPR109A, whereas GPR43 and GPR119 can be activated by acetate, butyrate and propionate at similar rates [70, 71]. The order Clostridiales provides the largest microbiota population towards the production of SCFAs including the genera Anaerostipes, Clostridium, Coprococcus, Dorea, Eubacterium, Faecalibacterium, Roseburia, Ruminococcus, Peptococcus, and Peptostreptococcus [72].

The activation of receptors GPR41 and GPR43 induces the secretion of peptide tyrosine-tyrosine (PYY), reducing host appetite by directly stimulating the central nervous system [73, 74]. GPR41 coupling has the ability to initiate the expression of leptin from adipocytes $[75,76]$ and was first discovered using GPR41 deficient mice that displayed substantially lower leptin levels than corresponding wild-type mice [77]. Leptin acts on the hypothalamus, reducing food intake by inhibiting the release of neuropeptide Y (NPY) and promotes an increase in host metabolic rate consequently enhancing energy expenditure.

GPR43 receptor coupling with acetate directly reduces lipolysis in adipocytes, decreasing plasma-free fatty acids suggesting a possible therapeutic role for receptor GPR43 in lipid metabolism regulation [78]. Studying wild-type rodents, the receptor GPR43 was found to be mainly expressed in immune and white adipose tissue (WAT). Observing the activation of GPR43 in WAT found that insulin-induced protein kinase $B$ (AKT)-

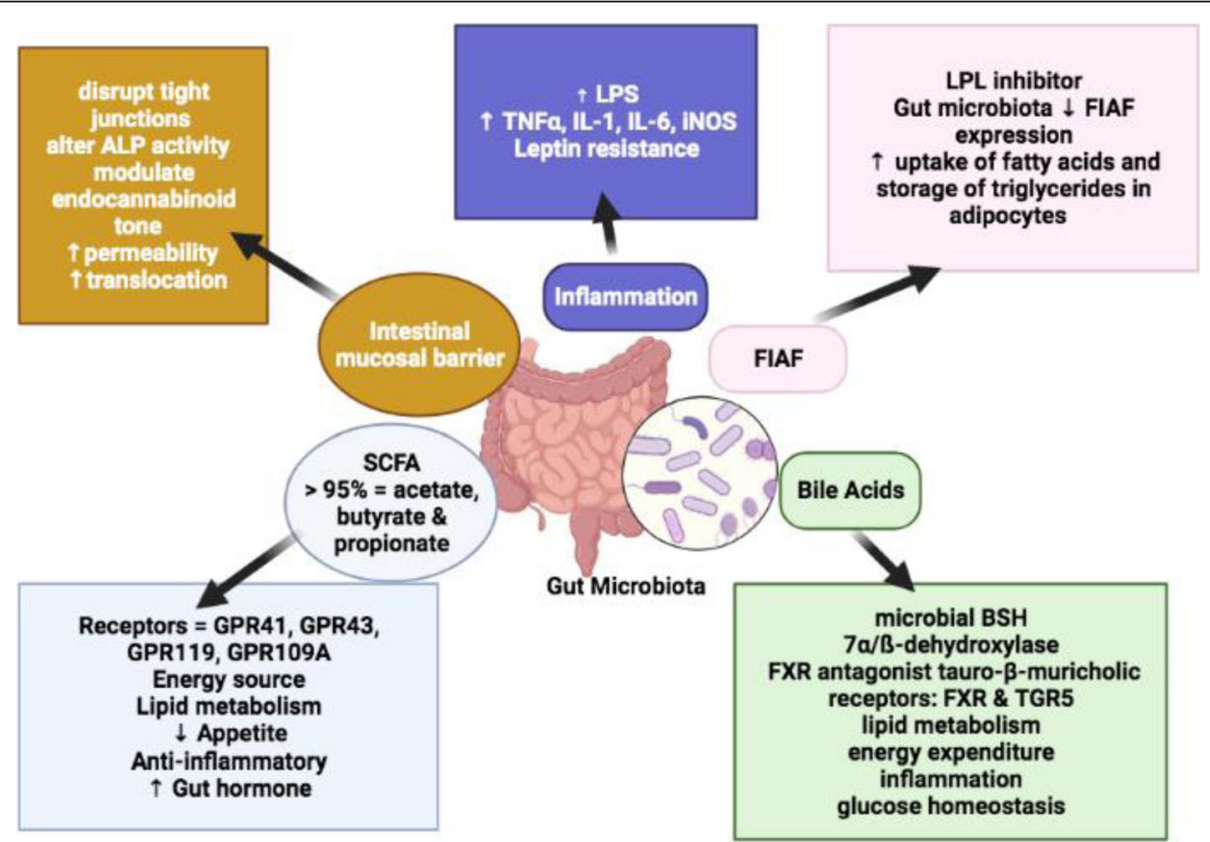

Fig. 2 Host metabolic pathways influenced by gut microbiota and metabolites including SCFAs, Fiaf inhibition, bile acid metabolism, intestinal mucosal barrier and host inflammatory pathway 
activation was significantly reduced, resulting in less fat accumulation. In conclusion, GPR43-deficient rodents are phenotypically obese in contrast to rodents with a specific overexpression of GPR43 in WAT, who remain lean even when subjected to a high calorific diet [38].

SCFA coupling with receptors GPR43 and GPR109A provides anti-inflammatory protection for the host. GPR43 coupling promotes the production of antimicrobial peptides RegIII $\gamma$ and $\beta$-defensin and immunityrelated cytokines such as interleukin (IL)-1, IL-6, IL-12 and IL-18 $[39,79]$. GPR109A activation suppresses colonic inflammation and carcinogenesis by promoting anti-inflammatory properties in colonic macrophages and dendritic cells, which induce the differentiation of regulatory and IL-10-producing $\mathrm{T}$ cells [80].

Acetate, the most abundant SCFA is produced by enteric bacteria from the genera Lactobacillus, Bifidobacterium, Akkermansia, Bacteroides, Prevotella, Ruminococcus and Streptococcus [81]. Acetate is readily absorbed, transported to the liver to be used as an energy source and also utilised as a substrate for the synthesis of cholesterol and long-chain fatty acids [82]. The presence of acetyl-coenzyme A synthetase in adipose tissue allows for the use of acetate in lipogenesis on entering the systemic circulation [64]. Large quantities of systemic acetate may enhance host production of the 'hunger hormone', ghrelin, which is released from enteroendocrine cells in the GIT worsening hunger, reducing metabolic rate and increasing gastric motility and gastric acid production [83].

Butyrate has particular importance in host homeostasis and may contribute to the regulation of body weight. The genera Anaerostipes, Clostridium, Coprococcus, Dorea, Eubacterium, Faecalibacterium, Roseburia and Ruminocococcus all produce butyrate. The most abundant producers appear to be the species Faecalibacterium prausnitzii, Eubacterium rectale and Roseburia intestinalis [84, 85]. Eubacterium and Anaerostipes have the ability to interact with Bifidobacterium to enhance their butyrate production capacity [86].

Butyrate promotes energy expenditure, possibly reducing obesity through the enhancement of mitochondrial activity (activates AMP-activated protein kinase, increasing adenosine triphosphate (ATP) consumption and the induction of peroxisome proliferator-activated receptor gamma coactivator one (PGC-1) activity), in association with the up-regulation of the expression of genes involved in lipolysis and fatty acid oxidation $[87,88]$. Butyrate supplementation in rodents maintained on a highcalorific diet has been observed to prevent the development of dietary obesity and insulin resistance [89]. At cellular level, butyrate was noted to increase mitochondrial respiration [89]. Butyrate may reduce energy intake by invoking a host anorectic response by increasing the plasma levels of glucagon-like peptide 1 (GLP-1), glucose dependent insulinotropic polypeptide (GIP) and PYY $[87,88]$.

Propionate is mainly produced by the genera Phascolarctobacterium, Bacteroides, Dialister, Megasphaera, Veillonella, Coprococcus, Roseburia, Ruminococcus and Salmonella [81]. Propionate stimulates the release of the anorectic gut hormones PYY and GLP-1 and has the ability to stimulate a gut-brain circuit through the action of receptor GPR41 thus leading to the induction of intestinal gluconeogenesis (IGN) gene expression. Upregulation of IGN by propionate reduces body weight gain and adiposity, independent of food intake [90]. Providing propionate supplementation, results in a reduction in weight, abdominal adipose tissue and hepatic fat; an improvement in insulin sensitivity; increased satiety and reduced appetite [91, 92].

\section{Reduced activity of fasting-induced adipose factor}

Fasting-induced adipose factor (Fiaf) is a circulating lipoprotein lipase (LPL) inhibitor produced by the intestine, liver and adipose tissue [93]. Gut microbiota efficiently suppress Fiaf expression in the ileum, enhancing the activity of LPL and increasing cellular uptake of fatty acids and storage of triglycerides in adipocytes [56]. LPL is the key enzyme that acts on the endothelial surface of extrahepatic capillaries, releasing large amounts of fatty acids from lipoproteins for the uptake of tissues for production or storage of energy [94]. Bäckhed et al., demonstrated that hepatic lipogenesis appears to be induced in conventionalised GF-mice (CONV-D). The importance of Fiaf in this regulatory pathway was clarified by comparing GF- Fiaf knockout (Fiaf-/-) rodents to their wild-type littermates. In the absence of Fiaf, rodents gained substantially more weight than their littermates due to enhanced LPL activity. It is therefore possible that a reduction in Fiaf activity was responsible for the increased adiposity in CONV-D mice [56].

\section{Bile acids}

Bile acids (BA) are cholesterol-derived metabolites produced in hepatocytes, which are conjugated to glycine or taurine and $95 \%$ reach the entero-hepatic circulation following reabsorption in the terminal ileum [95]. The primary BAs chenodeoxycholic acid (CDCA) and cholic acid (CA) are essential for lipid/vitamin digestion and absorption. Small quantities of primary BAs reach the colon where gut microbiota have the capability to convert them into secondary BAs through the processes of deconjugation, dehydroxylation, and reconjugation. Examples are deoxycholic acid (DCA), ursodeoxycholic (UDCA) and lithocholic acid (LCA) [96]. In the colon, conjugated $\mathrm{CA}$ and $\mathrm{CDCA}$ are deconjugated and then dehydroxylated at the $7 \alpha$-position for the formation of 
the secondary bile acids DCA and LCA, respectively [97].

BA deconjugation is catalysed through the enzymatic activity of bile salt hydrolases (BSH) found within gut microbiota particularly from the genera Lactobacillus, Bifidobacterium, Enterobacter, Bacteroides and Clostridium $[98,99]$. Microbial BSH is an enzyme which enhances BA intestinal reabsorption, promotes intestinal colonisation and can provide a nutritional source of sulfur, nitrogen and carbon [96]. Unlike BSH activity, only a small number of genera such as Clostridium and $\mathrm{Eu}$ bacterium possess the enzyme $7 \alpha / \beta$-dehydroxylase which participates in the conversion of primary to secondary BAs [96]. Gut microbiota also possess the capability to influence BA synthesis through the metabolism of the naturally occurring FXR antagonist tauro- $\beta$ muricholic acid [100, 101].

Disruption to the microbiota population strongly affects BA metabolism leading to a failure in the conversion of primary BAs, resulting in their accumulation [102, 103]. Both primary and secondary BAs exert their biological effects by activating nuclear and plasma membrane receptors (nuclear farnesoid X receptor (FXR) or the G protein-coupled receptor (TGR5)) which control the synthesis and metabolism of BAs. Primary BAs bind to the FXR receptor whereas secondary BAs bind to the TGR5 receptor [99]. Stimulation of these receptors initiates signaling cascades and activates gene expression involved in the regulation of glucose homeostasis, lipid metabolism, energy expenditure and inflammation [96, 104].

Receptor TGR5 is expressed in brown adipocytes, macrophages, hepatic Kupffer cells, gallbladder epithelium and the colon [105]. TGR5 signaling enhances energy expenditure in adipose tissue through the action of cyclic adenosine monophosphate (cAMP) increasing the induction of type 2 deiodinase (DIO2), which converts and activates thyroid hormone $\mathrm{T}_{4}$ to $\mathrm{T}_{3}$ to stimulate energy metabolism in mitochondria. In the colon, the action of cAMP stimulates the release of GLP-1 in L cells. TGR5 signaling also has the ability to suppress inflammation in macrophages, the intestine and hepatocytes by inhibiting nuclear factor kappa-light-chain-enhancer of activated B cells (NF$\mathrm{\kappa B})$ translocation, antagonising tumour necrosis factor alpha (TNF $\alpha)$ and NF-kB-dependent induction of proinflammatory cytokines [105].

Stimulation of the FXR receptor induces gene expression involved in lipogenesis and de novo cholesterol synthesis including apolipoprotein C-II, apolipoprotein E, peroxisome proliferator-activated receptor alpha (PPAR $\alpha)$ and syndecan-1 [105]. Secondly, FXR stimulation triggers a reduction in very low density lipoprotein (VLDL) production by inhibiting the mitochondria triglyceride transport protein which is necessary for the assembly of VLDL particles [102]. Thirdly, FXR receptor signaling improves reverse cholesterol transport by enhancing the activity of the phospholipid transport protein which transports cholesterol from peripheral tissues to the liver for the conversion into BAs, thus preventing the accumulation in macrophages. Lastly, FXR stimulation induces fibroblast growth factor 19 (FGF-19) synthesis which inhibits BA synthesis, increases host metabolic rate, induces the hepatic leptin receptor and increases fatty acid oxidation [105]. Introducing the FXR agonist obeticholic acid was found to improve obesityrelated disorders in an animal model [106].

The participation of the gut microbiota in the metabolism of BAs strengthen its role as a central regulator of lipid metabolism contributing to the progression of host obesity. Further research is required to clarify the central role of the gut microbiome in regulating BAs as an important mechanism towards the pathogenesis of obesity.

\section{Intestinal mucosal barrier}

The mucosal lining of the GIT acts as a preventative barrier, reducing undesirable interactions between the gut epithelium, viruses, toxins and pathogenic bacteria [107]. It is well established that obesity is associated with mucosal barrier dysfunction with increased permeability and greater levels of systemic LPS in obese rodents [48]. Disruption of the mucosal lining allows for the translocation of toxins, resulting in metabolic endotoxaemia and subsequent low-grade inflammation, autoimmunity and oxidative stress $[108,109]$.

Gut microbiota take part in colonisation resistance which reinforces the mucosal barrier against colonisation by pathogens and provide continuous stimulation of pathogen recognition receptors to increase the production of mucins and antimicrobial peptides [110]. Mucosal adherent microbiota, such as the species Akkermansia muciniphila, are important for homeostatic epithelial cell stimulation [24]. Other microbiota have also been consistently reported to benefit gut barrier function. Both the genus Roseburia and the species Faecali prausnitzii are important butyrate-producing microbes which are well understood in their ability to provide protection against bacterial translocation [50, 51]. Lastly, an increased abundance of the genus Bifidobacterium has been associated with reduced gut leakiness and a reduction in serum LPS [31, 48].

GIT mucosal function is maintained via several mechanisms including appropriate localisation and distribution of tight junction proteins, normal endocannabinoid system tone, and LPS detoxification by intestinal alkaline phosphatase. The presence of SCFAs enhances gut barrier integrity $[109,111]$. Gut microbiota have the ability to disrupt tight junction proteins, alter alkaline 
phosphatase activity and selectively modulate colonic expression of the cannabinoid receptor 1 (CB1), strongly impacting permeability through effects on zonula occludens-1 and occludin [112, 113]. Brun et al., analysed cross-sections of intestine obtained from obese rodents which demonstrated a reduction in the tight junction protein occludin and an irregular distribution of zonula occludens-1 [114].

\section{Inflammatory response}

Obesity is associated with a state of chronic low-grade inflammation with abnormal expression and production of multiple inflammatory mediators [115-117]. Inflammation in metabolic disease was first described by Hotamisligil et al., who demonstrated the ability of adipocytes to express the cytokine TNF $\alpha$ and that TNF $\alpha$ expression in adipocytes of obese animals is intensified [118]. Gut microbiota exacerbate inflammation through the activity of LPS, an essential component of the cell walls of Gram-negative bacteria [119-121]. The genera Fusobacterium, Escherichia-Shigella, Pseudomonas and Campylobacter are all prevalent in obesity [11, 26]. LPS from members of the families Enterobacteriaceae and Desulfovibrionaceae exhibit an endotoxin activity that is 1000fold greater than LPS from Bacteroideaceae [122].

Dietary fat, which is incorporated into triglycerides combines to form larger chylomicrons for systemic transportation, has a high affinity for LPS. Intestinal absorption of dietary fat therefore facilitates the direct movement of LPS into the systemic circulation [119]. Once in the circulation, LPS is recognised and triggers both the innate and local immune response and the subsequent release of pro-inflammatory molecules $\mathrm{TNF} \alpha$, IL-1, IL-6, and inducible nitric oxide synthase (iNOS) [16]. LPS is also believed to play a role in host development of leptin resistance [123], causing hyperphagia and weight gain, further increasing fat intake, raising LPS and leading to further inflammation [124].

Obese rodents exhibit significantly greater levels of plasma LPS than their lean counterparts and also display low-grade systemic inflammation [125]. Subcutaneous injection of the species Escherichia coli LPS into wildtype rodents maintained on standard chow produced the development of inflammation, obesity, fasted glycaemia and insulinaemia. Importantly, in cluster of differentiation 14 (CD14)-knockout mice, in which LPS cannot be recognised by the innate immune system, there was a reduction or even a complete lack of development of most features of metabolic diseases induced by high calorific chow or a LPS infusion [125].

\section{Microbiota population differences after bariatric surgery} Bariatric surgery is currently the only available treatment for morbid obesity that consistently achieves and sustains substantial weight loss [126]. The Roux-en-Y gastric bypass (RYGB), is the most commonly performed bariatric operation and involves the creation of a small gastric pouch from the fundus of the stomach. The distal stomach and proximal small intestine are bypassed by anastomosing the distal end of the midjejunum to the proximal gastric pouch (creating the Roux limb), and then reattaching the biliary and pancreatic limb at a specified distance along the Roux limb $[37,44]$. This procedure alters acid exposure to the gastric remnant and proximal small bowel, restricting the quantity and type of food that can be ingested comfortably and allows a degree of nutrient malabsorption by reducing the length of the small bowel. The resulting rise in $\mathrm{pH}$, increase in oxygen, downstream delivery of bile acids and consequent alteration in food ingestion may contribute to the changes seen in the gut microbiota population [37, 42, 44].

Gut microbiota changes after bariatric surgery have been reported in both rodent models and humans. No significant differences in diversity or relative abundance have been demonstrated between the differing bariatric procedures, a RYBG or sleeve gastrectomy [42]. In preparation for surgery, patients are instructed to follow a preoperative diet, which significantly adjusts the gut microbiota population. A reduction in the abundance of the families Streptococcaceae and Ruminococcaceae was noticed alongside a significant increase in Rikenellaceae and Bifidobacteriaceae [42]. After surgery, large increases in Gammaproteobacteria (96.2\% of which were members of the family Enterobacteriaceae), a proportional decrease in Firmicutes (the species Clostridium difficile, Clostridium hiranonis, and Gemella sanguinis), and a loss of methanogens was reported [37, 42, 43]. Several facultative anaerobes in the Proteobacteria (the genera Escherichia, Klebsiella, and Pseudomonas) were also discovered at enhanced levels [43, 44]. An increase in the abundance of the families Streptococcaceae and Veillonellaceae and a decline in Bifidobacteriaceae that persisted for at least six months after surgery have also been observed [42].

The Bacteroides/Prevotella population has been seen to increase and remain stable post-RYGB at a quantity seen in lean control subjects. The higher the increase in the proportions of Bacteroides/Prevotella, the greater the reduction in body fat mass and plasma leptin [44].

Performing a RYGB in a rodent model markedly alters the composition of the distal gut microbiota as early as one week after surgery, a change that progressed over time and stabilised after five weeks independent of diet [45]. Specific changes in the gut microbial community were demonstrated including enrichment in three distinct taxonomic groups; evident at phylum level-Bacteroidetes, Verrucomicrobia, and Proteobacteria; to 
genus level-Alistipes, Akkermansia, and Escherichia [45]. A substantial increase in the abundance of Proteobacteria specifically the species Enterobacter hormaechei and a reduction in Firmicutes and Bacteroidetes has also been observed [46].

Liou et al. [45], performed FMT procedures using microbiota extracted from rodents who had a RYGB procedure. The control arm facilitated mice that had received a sham RYGB. It was demonstrated that the rodent cohort who had received the treatment-FMT displayed substantial weight reduction and loss of fat mass compared to their counterparts receiving shamFMT [45]. Further research focusing on GF-rodents colonised with RYGB microbiota illustrates the accumulation of $43 \%$ less body fat and a lower respiratory quotient than rodents colonised with 'obese' microbiota. This particular finding suggests the reduction in usage of carbohydrates and increased utilisation of lipids as a potential energy source [43].. In both studies, a decrease in adiposity and body weight without a change in chow intake was observed suggesting RYGB-associated microbiota may either reduce the ability to harvest energy from the diet or produce signals regulating energy expenditure and lipid metabolism [45].

\section{Future manipulation of microbiota}

As the evolving exploration for causality between obesity and microbiota continues, attention has been diverted to the search for techniques in microbiota manipulation with the objective of restoring a balanced gut microbiota community. FMT techniques have been refined and involve the transfer of carefully screened faecal material containing microbiota from a healthy donor into an identified 'diseased' patient with the intention of cure [127]. Probiotics and prebiotics are also proposed methods to manipulate the gut microbiota population in order to improve metabolic conditions, however FMT is considered to have the potential for being more successful. FMT has the ability to transfer entire donor microbiota communities, including their metabolites, to the identified recipient, with the perceived enhanced capability to correct microbiota disruption over single microbial targets such as probiotic supplementation [128].

FMT studies aiming to improve metabolic parameters are increasing in number. Vrieze et al., were the first group (2012) to perform human FMT using treatment-naive subjects diagnosed with metabolic syndrome [47]. Eighteen subjects were randomised to receive either FMT produced from lean male donors $(\mathrm{BMI}<23)$ or autologous transfusions. Subjects who received allogenic transfusions were noted to have improved peripheral insulin sensitivity (after 6 weeks) but this effect deteriorated with time and there was considerable individual variability. Allogenic recipients demonstrated higher abundances of butyrateproducing bacteria (the species Roseburia intestinalis) post-treatment [47].

Two randomised studies investigated the effects of using lean allogenic FMT in subjects diagnosed with metabolic syndrome $[129,130]$. Both studies failed to show any improvement in metabolic parameters or subject physiology. However, it was noted that recipients of the lean allogenic FMT mostly, but not all were found to have gut microbiota composition that shifted towards an appearance similar to the donor's profile implying unsuccessful engraftment [129, 130] (see Table 2).

It has been estimated that a sample size of 1700 subjects per study is likely needed to adequately assess the relationship between obesity and microbiota composition after correcting for variables (17). Of the research that has already been completed, carefully controlled FMT has satisfied the safety requirements but with underwhelming clinical findings at present. FMT has demonstrated its potential for restoring both gut-microbiota composition and functionality however better understanding of the mechanisms through which these alterations translate into metabolic outcomes is still unknown. With the continued introduction of advancing technology and an ever-increasing co-morbid population, further exploration is still required for the clarification of gut microbiota causality before the routine establishment of microbiota manipulation occurs.

\section{Study strengths and limitations}

This review updates previous literature by bringing together the central microbiomic theories underpinning obesity from a metabolome perspective. It is limited by a persistent lack of consensus understanding of the mechanistics by which the microbiota exert their obesogenic effect, and given the heterogeneity of the literature was conducted in a nonsystematic way.

\section{Conclusion}

The gut microbiota has enormous metabolic capacity behaving as a central modulator in the contribution towards obesity. Research clearly indicates significant discrepancies in determining the cause or effect relationship between the gut microbiota and obesity. The relationship has partly been established at structural level, however it seems that functionality rather than the composition of microbiota populations may contain the answers to the mechanisms underlying obesity. This review has discussed central mechanisms involving the gut 
Table 2 Faecal Microbiota Transplantation usage in human studies of obesity/metabolic syndrome

\begin{tabular}{|c|c|c|c|c|c|c|c|c|}
\hline Paper & $\begin{array}{l}\text { No. } \\
\text { patient }\end{array}$ & Demographic & $\begin{array}{l}\text { Type of } \\
\text { study }\end{array}$ & $\begin{array}{l}\text { Mode of } \\
\text { delivery }\end{array}$ & $\begin{array}{l}\text { Country of } \\
\text { Study }\end{array}$ & $\begin{array}{l}\text { Frozen / } \\
\text { fresh }\end{array}$ & Outcomes & $\begin{array}{l}\text { Significant } \\
\text { Adverse } \\
\text { Events }\end{array}$ \\
\hline $\begin{array}{l}\text { Allegretti } \\
\text { et al. } \\
\text { [129] }\end{array}$ & $\begin{array}{l}22 \\
11= \\
\text { allogenic } \\
\text { lean FMT } \\
11= \\
\text { placebo }\end{array}$ & $\begin{array}{l}\text { Obese } \mathrm{BMI}>35 \\
\text { without metabolic } \\
\text { complications }\end{array}$ & $\begin{array}{l}\text { DBRCT* } \\
1: 1\end{array}$ & Capsules & USA & $\begin{array}{l}\text { Unrelated } \\
\text { donor } \\
\text { Frozen } \\
\text { stool }\end{array}$ & $\begin{array}{l}\text { No change in GLP1 in either } \\
\text { group } \\
\text { No significant changes in } \\
\text { obesity biomarkers } \\
\text { No changes in BMI } \\
\text { Sustained shift of } \\
\text { microbiome towards donor } \\
\text { profile }\end{array}$ & Nil \\
\hline $\begin{array}{l}\text { Vrieze } \\
\text { et al. [47] }\end{array}$ & $\begin{array}{l}18 \\
9=\text { Lean } \\
\text { allogenic } \\
9= \\
\text { autologous } \\
\text { FMT }\end{array}$ & $\begin{array}{l}\text { Treatment naïve } \\
\text { males with } \\
\text { metabolic } \\
\text { syndrome }\end{array}$ & $\begin{array}{l}\mathrm{RCT}^{*} \text { placebo } \\
\text { controlled } \\
\text { pilot study } \\
1: 1\end{array}$ & $\begin{array}{l}\text { Nasoduodenal } \\
\text { tube }\end{array}$ & Netherlands & $\begin{array}{l}\text { Unrelated } \\
\text { donor } \\
\text { Fresh } \\
\text { stool }\end{array}$ & $\begin{array}{l}\text { Improvement in peripheral } \\
\text { insulin sensitivity at } 6 \text { weeks } \\
\text { in allogenic FMT } \\
\text { Gut bacterial diversity } \\
\text { significantly increased post } \\
\text { allogenic FMT }\end{array}$ & Nil \\
\hline $\begin{array}{l}\text { Smits } \\
\text { et al. } \\
\text { [130] }\end{array}$ & $\begin{array}{l}20 \\
10= \\
\text { allogenic } \\
\text { lean vegan } \\
\text { FMT } \\
10= \\
\text { autologous } \\
\text { FMT }\end{array}$ & $\begin{array}{l}\text { Male cohort with } \\
\text { metabolic } \\
\text { syndrome }\end{array}$ & $\begin{array}{l}\text { DBRCT pilot } \\
\text { study } \\
1: 1\end{array}$ & $\begin{array}{l}\text { Nasoduodenal } \\
\text { tube }\end{array}$ & Netherlands & $\begin{array}{l}\text { Unrelated } \\
\text { donor } \\
\text { Fresh } \\
\text { stool }\end{array}$ & $\begin{array}{l}\text { No changes in faecal } \\
\text { diversity } 2 \text { weeks post FMT } \\
\text { Allogenic FMT shifted } \\
\text { microbiome profile towards } \\
\text { vegan } \\
\text { No changes in vascular } \\
\text { inflammation }\end{array}$ & Nil \\
\hline
\end{tabular}

DBRCT: double-blinded randomised control trial, RCT: randomised control trial

microbiota in their ability to promote obesity development such as the inhibition of Fiaf, altered production of SCFAs, heightened inflammatory pathways, increased gut permeability with resulting endotoxaemia, and disrupted BA metabolism as future druggable and modifiable targets. Given the increasing output of controlled research we should soon have a better understanding of the gut microbiota:obesity association and whether clinically modulating the gut microbiome through FMT will provide a new therapeutic option for the management of this complex disorder.

\begin{abstract}
Abbreviations
AKT: protein kinase B; ATP: adenosine triphosphate; BA: bile acid; BMI: body mass index; BSH: bile salt hydrolases; CA: cholic acid; CAMP: cyclic adenosine monophosphate; CB1: cannabinoid receptor type-1; CD14: cluster of differentiation 14; CDCA: chenodeoxycholic acid; CONV-D: conventionalised GF-mice; DCA: deoxycholic acid; DIO2: type 2 deiodinase; Fiaf: fastinginduced adipose factor; FGF-19: fibroblast growth factor 19; FXR: farnesoid X receptor; FMT: faecal microbiota transplant; GF: germ free; GIP: glucose dependent insulinotropic polypeptide; GIT: gastrointestinal tract; GLP-

1: glucagon-like peptide 1; GPR: G protein coupled receptor; $\mathrm{H}_{2}$ : hydrogen; IGN: intestinal gluconeogenesis; IL: interleukin; iNOS: inducible nitric oxide synthase; Kg: kilograms; LBL: lipoprotein lipase; LCA: lithocholic acid; LGC: low gene count; LPS: lipopolysaccharide; NF- KB: nuclear factor kappa-light-chainenhancer of activated B cells; NPY: neuropeptide Y; RYGB: Roux-en-Y gastric bypass; PGC-1: peroxisome proliferator-activated receptor gamma coactivator one; PPARa: peroxisome proliferator-activated receptor alpha; PYY: peptide tyrosine-tyrosine; SCFA: short chain fatty acid; TGR5: G protein-coupled receptor; TNF: tumour necrosis factor; UDCA: ursodeoxycholic acid; VLDL: very low density lipoprotein; WAT: white adipose tissue
\end{abstract}

\section{Authors' contributions}

AC performed the relevant background / literature searches for the major construction of this review. DH and JS were major contributors in the editing of this paper. All authors read and approved the final manuscript.

Funding

The authors deny any source of funding for the development of this work.

\section{Availability of data and materials}

Data sharing not applicable to this article as no datasets were generated or analysed during the completion of this review.

\section{Declarations}

Ethics approval and consent to participate

Not applicable.

\section{Consent for publication}

All authors consent to this publication.

\section{Competing interests}

The authors declare that they have no financial or non-financial competing interests.

Received: 9 April 2021 Accepted: 17 June 2021

Published online: 07 July 2021

References

1. : World Health Organisation. Obesity and overweight. 2020. https://www. who.int/news-room/fact-sheets/detail/obesity-and-overweight. Accessed 17 March 2021.

2. Power ML, Schulkin J. The evolution of obesity. Baltimore: The Johns Hopkins University Press; 2009

3. World Health Organisation. Obesity. https://www.who.int/health-topics/ obesity\#tab=tab_1. Accessed 17 Mar 2021.

4. : Komaroff AL. The microbiome and risk for obesity and diabetes. JAMA. 2017;317(4):355-356, DOl: https://doi.org/10.1001/jama.2016.20099. 
5. Canfora EE, Jocken JW, Blaak EE. Short-chain fatty acids in control of body weight and insulin sensitivity. Nat Rev Endocrinol. 2015;11(10):577-91. https://doi.org/10.1038/nrendo.2015.128.

6. Bested AC, Logan AC, Selhub EM. Intestinal microbiota, probiotics and mental health: from Metchnikoff to modern advances: part III - convergence toward clinical trials. Gut Pathog. 2013;5(1):4. https://doi.org/10.1186/1757-4 749-5-4

7. Harsch IA, Konturek PC. The role of gut microbiota in obesity and type 2 and type 1 diabetes mellitus: new insights into "old" diseases. Med Sc (Basel). 2018:6(2):32.

8. Turnbaugh PJ, Ley RE, Hamady M, Fraser-Liggett CM, Knight R, Gordon Jl. The human microbiome project. Nature. 2007;449(7164):804-10. https://doi. org/10.1038/nature06244

9. Parks DH, Chuvochina M, Waite DW, Rinke C, Skarshewski A, Chaumeil PA, et al. A standardized bacterial taxonomy based on genome phylogeny substantially revises the tree of life. Nat Biotechnol. 2018;36(10):996-1004. https://doi.org/10.1038/nbt.4229.

10. Schwiertz A, Taras D, Schäfer K, Beijer S, Bos NA, Donus C, et al. Microbiota and SCFA in lean and overweight healthy subjects. Obesity (Silver Spring). 2010;18(1):190-5. https://doi.org/10.1038/oby.2009.167.

11. Gao R, Zhu C, Li H, Yin M, Pan C, Huang L, et al. Dysbiosis signatures of gut microbiota along the sequence from healthy, young patients to those with overweight and obesity. Obesity (Silver Spring). 2018;26(2):351-61. https:// doi.org/10.1002/oby.22088.

12. Abenavoli L, Scarpellini E, Colica C, et al. Gut microbiota and obesity: a role for probiotics. Nutrients. 2019;11(11):2690.

13. Delzenne NM, Cani PD. Gut microbiota and the pathogenesis of insulin resistance. Curr Diab Rep. 2011;11(3):154-9. https://doi.org/10.1007/s11892011-0191-1.

14. Kootte RS, Vrieze A, Holleman F, Dallinga-Thie GM, Zoetendal EG, de Vos WM, et al. The therapeutic potential of manipulating gut microbiota in obesity and type 2 diabetes mellitus. Diabetes Obes Metab. 2012;14(2):11220. https://doi.org/10.1111/j.1463-1326.2011.01483.x.

15. Blaut M. Ecology and physiology of the intestinal tract. Curr Top Microbiol Immunol. 2013;358:247-72.

16. Saad MJ, Santos A, Prada PO. Linking gut microbiota and inflammation to obesity and insulin resistance. Physiology (Bethesda). 2016;31(4):283-93. https://doi.org/10.1152/physiol.00041.2015

17. Falony $G$, Joossens M, Vieira-Silva S, Wang J, Darzi Y, Faust K, et al. Population-level analysis of gut microbiome variation. Science. 2016; 352(6285):560-4. https://doi.org/10.1126/science.aad3503.

18. Murphy EF, Cotter PD, Healy S, Marques TM, O'Sullivan O, Fouhy F, et al. Composition and energy harvesting capacity of the gut microbiota: relationship to diet, obesity and time in mouse models. Gut. 2010;59(12): 1635-42. https://doi.org/10.1136/gut.2010.215665.

19. Vangay $\mathrm{P}$, Johnson AJ, Ward TL, et al. US Immigration Westernizes the Human Gut Microbiome. Cell. 2018;175(4):962-972.e10.

20. De Angelis M, Ferrocino I, Calabrese FM, et al. Diet influences the functions of the human intestinal microbiome. Sci Rep. 2020;10(1):4247. https://doi. org/10.1038/s41598-020-61192-y.

21. Turnbaugh PJ, Hamady M, Yatsunenko T, Cantarel BL, Duncan A, Ley RE, et al. A core gut microbiome in obese and lean twins. Nature. 2009; 457(7228):480-4

22. Remely M, Tesar I, Hippe B, Gnauer S, Rust P, Haslberger AG. Gut microbiota composition correlates with changes in body fat content due to weight loss. Benef Microbes. 2015;6(4):431-9. https://doi.org/10.3920/BM2014.0104.

23. Rastelli M, Knauf C, Cani PD. Gut microbes and health: a focus on the mechanisms linking microbes, obesity, and related disorders. Obesity (Silver Spring). 2018;26(5):792-800. https://doi.org/10.1002/oby.22175.

24. Dao MC, Everard A, Aron-Wisnewsky J, Sokolovska N, Prifti E, Verger EO, et al. Akkermansia muciniphila and improved metabolic health during a dietary intervention in obesity: relationship with gut microbiome richness and ecology. Gut. 2016;65(3):426-36. https://doi.org/10.1136/gutjnl-2014-3 08778.

25. Turnbaugh PJ, Bäckhed F, Fulton L, Gordon Jl. Diet-induced obesity is linked to marked but reversible alterations in the mouse distal gut microbiome. Cell Host Microbe. 2008;3(4):213-23. https://doi.org/10.1016/j.chom.2008.02 015 .

26. Le Chatelier E, Nielsen T, Qin J, Prifti E, Hildebrand F, Falony G, et al. Richness of human gut microbiome correlates with metabolic markers. Nature. 2013;500(7464):541-6.
27. Aron-Wisnewsky J, Prifti E, Belda E, Ichou F, Kayser BD, Dao MC, et al. Major microbiota dysbiosis in severe obesity: fate after bariatric surgery. Gut. 2019; 68(1):70-82.

28. Cotillard A, Kennedy SP, Kong LC, Prifti E, Pons N, le Chatelier E, et al. Dietary intervention impact on gut microbial gene richness. Nature. 2013; 500(7464):585-8. https://doi.org/10.1038/nature12480.

29. Vallianou N, Stratigou T, Christodoulatos GS, Dalamaga M. Understanding the role of the gut microbiome and microbial metabolites in obesity and obesity-associated metabolic disorders: current evidence and perspectives. Curr Obes Rep. 2019;8(3):317-32. https://doi.org/10.1007/s13679-019-003 $52-2$.

30. Collado MC, Isolauri E, Laitinen K, Salminen S. Distinct composition of gut microbiota during pregnancy in overweight and normal-weight women. Am J Clin Nutr. 2008;88(4):894-9. https://doi.org/10.1093/ajcn/88.4.894.

31. Singh RK, Chang HW, Yan D, Lee KM, Ucmak D, Wong K, et al. Influence of diet on the gut microbiome and implications for human health. J Transl Med. 2017;15(1):73.

32. Goodrich JK, Waters JL, Poole AC, Sutter JL, Koren O, Blekhman R, et al. Human genetics shape the gut microbiome. Cell. 2014;159(4):789-99. https://doi.org/10.1016/j.cell.2014.09.053.

33. Zhernakova A, Kurilshikov A, Bonder MJ, Tigchelaar EF, Schirmer M, Vatanen $T$, et al. Population-based metagenomics analysis reveals markers for gut microbiome composition and diversity. Science. 2016;352(6285):565-9. https://doi.org/10.1126/science.aad3369.

34. Louis S, Tappu RM, Damms-Machado A, Huson DH, Bischoff SC. Characterization of the gut microbial Community of Obese Patients Following a weight-loss intervention using whole metagenome shotgun sequencing. PLoS One. 2016;11(2):e0149564. https://doi.org/10.1371/journal. pone. 0149564 .

35. Hippe B, Remely M, Aumueller E, Pointner A, Magnet U, Haslberger AG. Faecalibacterium prausnitzii phylotypes in type two diabetic, obese, and lean control subjects. Benef Microbes. 2016;7(4):511-7. https://doi.org/10.392 0/BM2015.0075.

36. Alemán JO, Bokulich NA, Swann JR, Walker JM, De Rosa JC, Battaglia T, et al. Fecal microbiota and bile acid interactions with systemic and adipose tissue metabolism in diet-induced weight loss of obese postmenopausal women. J Transl Med. 2018;16(1):244.

37. Zhang H, DiBaise JKK, Zuccolo A, Kudrna D, Braidotti M, Yu Y, et al. Human gut microbiota in obesity and after gastric bypass. Proc Natl Acad Sci U S A. 2009;106(7):2365-70. https://doi.org/10.1073/pnas.0812600106.

38. Kimura I, Ozawa K, Inoue D, Imamura T, Kimura K, Maeda T, et al. The gut microbiota suppresses insulin-mediated fat accumulation via the short-chain fatty acid receptor GPR43. Nat Commun. 2013;4(1):1829. https://doi.org/10.1 038/ncomms2852.

39. Zhao Y, Chen F, Wu W, Sun M, Bilotta AJ, Yao S, et al. GPR43 mediates microbiota metabolite SCFA regulation of antimicrobial peptide expression in intestinal epithelial cells via activation of MTOR and STAT3. Mucosal Immunol. 2018;11(3):752-62. https://doi.org/10.1038/mi.2 017.118.

40. Pallister T, Jackson MA, Martin TC, Glastonbury CA, Jennings A, Beaumont M, et al. Untangling the relationship between diet and visceral fat mass through blood metabolomics and gut microbiome profiling. Int J Obes. 2017:41(7):1106-13. https://doi.org/10.1038/ijo.2017.70.

41. Kalliomäki M, Collado MC, Salminen S, Isolauri E. Early differences in fecal microbiota composition in children may predict overweight. Am J Clin Nutr. 2008;87(3):534-8. https://doi.org/10.1093/ajcn/87.3.534.

42. Paganelli FL, Luyer M, Hazelbag CM, Uh HW, Rogers MRC, Adriaans D, et al. Roux-Y gastric bypass and sleeve gastrectomy directly change gut microbiota composition independent of surgery type. Sci Rep. 2019;9(1): 10979. https://doi.org/10.1038/s41598-019-47332-z.

43. Tremaroli V, Karlsson F, Werling M, Ståhlman M, Kovatcheva-Datchary P, Olbers T, et al. Roux-en-Y gastric bypass and vertical banded Gastroplasty induce long-term changes on the human gut microbiome contributing to fat mass regulation. Cell Metab. 2015;22(2):228-38.

44. Furet JP, Kong LC, Tap J, Poitou C, Basdevant A, Bouillot JL, et al. Differential adaptation of human gut microbiota to bariatric surgery-induced weight loss: links with metabolic and low-grade inflammation markers. Diabetes. 2010;59(12):3049-57. https://doi.org/10.2337/db10-0253.

45. Liou AP, Paziuk M, Luevano JM Jr, Machineni S, Turnbaugh PJ, Kaplan LM. Conserved shifts in the gut microbiota due to gastric bypass reduce host weight and adiposity. Sci Transl Med. 2013;5(178):178ra41. 
46. Li JV, Ashrafian H, Bueter M, Kinross J, Sands C, le Roux CW, et al. Metabolic surgery profoundly influences gut microbial-host metabolic cross-talk. Gut. 2011;60(9):1214-23.

47. Vrieze A, Van Nood E, Holleman F, Salojärvi J, Kootte RS, Bartelsman JF, et al. Transfer of intestinal microbiota from lean donors increases insulin sensitivity in individuals with metabolic syndrome. Gastroenterology. 2012; 143(4):913-6.e7.

48. Cani PD, Possemiers S, Van de Wiele T, Guiot Y, Everard A, Rottier O, et al. Changes in gut microbiota control inflammation in obese mice through a mechanism involving GLP-2-driven improvement of gut permeability. Gut. 2009;58(8):1091-103. https://doi.org/10.1136/gut.2008.165886.

49. Beaumont M, Goodrich JK, Jackson MA, Yet I, Davenport ER, Vieira-Silva S, et al. Heritable components of the human fecal microbiome are associated with visceral fat. Genome Biol. 2016;17(1):189.

50. Hansen J, Gulati A, Sartor RB. The role of mucosal immunity and host genetics in defining intestinal commensal bacteria. Curr Opin Gastroenterol. 2010;26(6):564-71.

51. Moran-Ramos S, López-Contreras BE, Canizales-Quinteros S. Gut microbiota in obesity and metabolic abnormalities: a matter of composition or functionality? Arch Med Res. 2017;48(8):735-53. https://doi.org/10.1016/j.a rcmed.2017.11.003

52. Krajmalnik-Brown R, llhan ZE, Kang DW, DiBaise JK. Effects of gut microbes on nutrient absorption and energy regulation. Nutr Clin Pract. 2012;27(2): 201-14.

53. Schleifer $\mathrm{KH}$. Classification of Bacteria and archaea: past, present and future. Syst Appl Microbiol. 2009;32(8):533-42. https://doi.org/10.1016/j.syapm.2009. 09.002.

54. Bauchop T, Mountfort DO. Cellulose fermentation by a rumen anaerobic fungus in both the absence and the presence of rumen methanogens. Appl Environ Microbiol. 1981;42(6):1103-10. https://doi.org/10.1128/aem.42. 6.1103-1110.1981.

55. Bäckhed F, Manchester JK, Semenkovich CF, Gordon Jl. Mechanisms underlying the resistance to diet-induced obesity in germ-free mice. Proc Natl Acad Sci U S A. 2007;104(3):979-84. https://doi.org/10.1073/pnas.06053 74104.

56. Bäckhed F, Ding H, Wang T, Hooper LV, Koh GY, Nagy A, et al. The gut microbiota as an environmental factor that regulates fat storage. Proc Nat Acad Sci U S A. 2004 Nov 2;101(44):15718-23. https://doi.org/10.1073/pnas. 0407076101.

57. Lupp C, Skipper M, Weiss U. Gut microbes and health. Nature. 2012; 489(7415):219

58. Turnbaugh PJ, Ley RE, Mahowald MA, Magrini V, Mardis ER, Gordon JI. An obesity-associated gut microbiome with increased capacity for energy harvest. Nature. 2006;444(7122):1027-31. https://doi.org/10.1038/na ture05414.

59. Ridaura VK, Faith JJ, Rey FE, Cheng J, Duncan AE, Kau AL, et al. Gut microbiota from twins discordant for obesity modulate metabolism in mice. Science. 2013;341(6150):1241214. https://doi.org/10.1126/science.1241214.

60. Clemente JC, Ursell LK, Parfrey LW, Knight R. The impact of the gut microbiota on human health: an integrative view. Cell. 2012;148(6):1258-70. https://doi.org/10.1016/j.cell.2012.01.035

61. Kau AL, Ahern PP, Griffin NW, Goodman AL, Gordon Jl. Human nutrition, the gut microbiome and the immune system. Nature. 2011;474(7351):327-36.

62. Cani PD. Metabolism in 2013: the gut microbiota manages host metabolism. Nat Rev Endocrinol. 2014;10(2):74-6. https://doi.org/10.1038/ nrendo.2013.240

63. Roy CC, Kien CL, Bouthillier L, Levy E. Short-chain fatty acids: ready for prime time? Nutr Clin Pract. 2006;21(4):351-66. https://doi.org/10.1177/011542 6506021004351

64. Cook SI, Sellin JH. Review article: short chain fatty acids in health and disease. Aliment Pharmacol Ther. 1998;12(6):499-507. https://doi.org/10.104 6/j.1365-2036.1998.00337.x.

65. Maslowski KM, Vieira AT, Ng A, Kranich J, Sierro F, Yu D, et al. Regulation of inflammatory responses by gut microbiota and chemoattractant receptor GPR43. Nature. 2009;461(7268):1282-6. https://doi.org/10.1038/nature08530.

66. Martin FP, Wang Y, Sprenger N, Yap IK, Lundstedt T, Lek $P$, et al. Probiotic modulation of symbiotic gut microbial-host metabolic interactions in a humanized microbiome mouse model. Mol Syst Biol. 2008;4:157.

67. Hamer HM, Jonkers D, Venema K, Vanhoutvin S, Troost FJ, Brummer RJ. Review article: the role of butyrate on colonic function. Aliment Pharmacol Ther. 2008;27(2):104-19. https://doi.org/10.1111/j.1365-2036.2007.03562.x.
68. Le Poul E, Loison C, Struyf S, Springael JY, Lannoy V, Decobecq ME, et al. Functional characterization of human receptors for short chain fatty acids and their role in polymorphonuclear cell activation. J Biol Chem. 2003; 278(28):25481-9.

69. Husted AS, Trauelsen M, Rudenko O, Hjorth SA, Schwartz TW. GPCRmediated signaling of metabolites. Cell Metab. 2017:25(4):777-96.

70. Ahmed K, Tunaru S, Offermanns S. GPR109A, GPR109B and GPR81, a family of hydroxy-carboxylic acid receptors. Trends Pharmacol Sci. 2009;30(11):557-62.

71. Brown AJ, Goldsworthy SM, Barnes AA, Eilert MM, Tcheang L, Daniels D, et al. The orphan G protein-coupled receptors GPR41 and GPR43 are activated by propionate and other short chain carboxylic acids. J Biol Chem 2003;278(13):11312-9. https://doi.org/10.1074/jbc.M211609200.

72. Collins MD, Lawson PA, Willems A, et al. The phylogeny of the genus Clostridium: proposal of five new genera and eleven new species combinations. Int J Syst Bacteriol. 1994;44(4):812-26. https://doi.org/10.1099/ 00207713-44-4-812.

73. Tazoe H, Otomo Y, Kaji I, Tanaka R, Karaki SI, Kuwahara A. Roles of shortchain fatty acids receptors, GPR41 and GPR43 on colonic functions. J Physiol Pharmacol. 2008;59(Suppl 2):251-62.

74. Tolhurst G, Heffron H, Lam YS, Parker HE, Habib AM, Diakogiannaki E, et al. Short-chain fatty acids stimulate glucagon-like peptide-1 secretion via the G-protein-coupled receptor FFAR2. Diabetes. 2012;61(2):364-71. https://doi. org/10.2337/db11-1019.

75. Karaki S, Tazoe H, Hayashi H, Kashiwabara H, Tooyama K, Suzuki Y, et al. Expression of the short-chain fatty acid receptor, GPR43, in the human colon. J Mol Histol. 2008;39(2):135-42. https://doi.org/10.1007/s10735-007-9145-y.

76. Xiong Y, Miyamoto N, Shibata K, Valasek MA, Motoike T, Kedzierski RM, et al. Short-chain fatty acids stimulate leptin production in adipocytes through the G protein-coupled receptor GPR41. Proc Natl Acad Sci U S A. 2004; 101(4):1045-50. https://doi.org/10.1073/pnas.2637002100.

77. Samuel BS, Shaito A, Motoike T, Rey FE, Backhed F, Manchester JK, et al. Effects of the gut microbiota on host adiposity are modulated by the shortchain fatty-acid binding G protein-coupled receptor, Gpr41. Proc Natl Acad Sci U S A. 2008;105(43):16767-72. https://doi.org/10.1073/pnas.0808567105.

78. Ge H, Li X, Weiszmann J, Wang P, Baribault H, Chen JL, et al. Activation of G protein-coupled receptor 43 in adipocytes leads to inhibition of lipolysis and suppression of plasma free fatty acids. Endocrinology. 2008;149(9): 4519-26. https://doi.org/10.1210/en.2008-0059.

79. Kim MH, Kang SG, Park JH, Yanagisawa M, Kim CH. Short-chain fatty acids activate GPR41 and GPR43 on intestinal epithelial cells to promote inflammatory responses in mice. Gastroenterology. 2013;145(2):396-406.e1-10.

80. Singh N, Gurav A, Sivaprakasam S, Brady E, Padia R, Shi H, et al. Activation of Gpr109a, receptor for niacin and the commensal metabolite butyrate, suppresses colonic inflammation and carcinogenesis. Immunity. 2014;40(1): 128-39. https://doi.org/10.1016/j.immuni.2013.12.007.

81. Feng $W, A o H$, Peng C. Gut microbiota, short-chain fatty acids, and herbal medicines. Front Pharmacol. 2018;9:1354. https://doi.org/10.3389/fphar.2018. 01354.

82. den Besten G, van Eunen K, Groen AK, Venema K, Reijngoud DJ, Bakker BM. The role of short-chain fatty acids in the interplay between diet, gut microbiota, and host energy metabolism. J Lipid Res. 2013;54(9):2325-40. https://doi.org/10.1194/jlr.R036012.

83. Perry RJ, Peng L, Barry NA, Cline GW, Zhang D, Cardone RL, et al. Acetate mediates a microbiome-brain- $\beta$-cell axis to promote metabolic syndrome. Nature. 2016:534(7606):213-7. https://doi.org/10.1038/nature18309.

84. Louis P, Flint HJ. Diversity, metabolism and microbial ecology of butyrateproducing bacteria from the human large intestine. FEMS Microbiol Lett. 2009;294(1):1-8

85. Hiippala $\mathrm{K}$, Jouhten $\mathrm{H}$, Ronkainen $\mathrm{A}$, et al. The potential of gut commensals in reinforcing intestinal barrier function and alleviating inflammation. Nutrients. 2018;10(8):988.

86. Turroni F, Milani C, Duranti S, Mahony J, van Sinderen D, Ventura M. Glycan utilization and cross-feeding activities by Bifidobacteria. Trends Microbiol. 2018:26(4):339-50.

87. Lin HV, Frassetto A, Kowalik EJ Jr, et al. Butyrate and propionate protect against diet-induced obesity and regulate gut hormones via free fatty acid receptor 3-independent mechanisms. PLoS One. 2012;7(4):e35240. https:// doi.org/10.1371/journal.pone.0035240.

88. Coppola S, Avagliano C, Calignano A, Berni Canani R. The Protective Role of Butyrate against Obesity and Obesity-Related Diseases. Molecules. 2021;26(3): 682. Published 2021 Jan 28. doi:https://doi.org/10.3390/molecules26030682 
89. Gao Z, Yin J, Zhang J, Ward RE, Martin RJ, Lefevre M, et al. Butyrate improves insulin sensitivity and increases energy expenditure in mice. Diabetes. 2009;58(7):1509-17.

90. Chambers ES, Viardot A, Psichas A, et al. Effects of targeted delivery of propionate to the human colon on appetite regulation, body weight maintenance and adiposity in overweight adults. Gut. 2015;64(11):1744-54

91. De Vadder F, Kovatcheva-Datchary P, Goncalves D, Vinera J, Zitoun C, Duchampt A, et al. Microbiota-generated metabolites promote metabolic benefits via gut-brain neural circuits. Cell. 2014;156(1-2):84-96. https://doi. org/10.1016/j.cell.2013.12.016.

92. Alhabeeb H, Chambers E, Frost G, Morrison D, Preston T. Inulin propionate ester increases satiety and decreases appetite but does not affect gastric emptying in healthy humans. Proceedings of the Nutrition Society. 2014; 73(OCE1):E21

93. Yoon JC, Chickering TW, Rosen ED, Dussault B, Qin Y, Soukas A, et al. Peroxisome proliferator-activated receptor gamma target gene encoding a novel angiopoietin-related protein associated with adipose differentiation. Mol Cell Biol. 2000;20(14):5343-9.

94. Sposito AC, Zimetti F, Barreto J, Zanotti I. Lipid trafficking in cardiovascular disease. Adv Clin Chem. 2019;92:105-40. https://doi.org/10.1016/bs.acc.2019.04. 002.

95. Thomas C, Gioiello A, Noriega L, Strehle A, Oury J, Rizzo G, et al. TGR5mediated bile acid sensing controls glucose homeostasis. Cell Metab. 2009; 10(3):167-77.

96. Grüner N, Mattner J. Bile acids and microbiota: multifaceted and versatile regulators of the liver-gut Axis. Int J Mol Sci. 2021;22(3):1397. https://doi. org/10.3390/ijms22031397.

97. Ma H, Patti ME. Bile acids, obesity, and the metabolic syndrome. Best Pract Res Clin Gastroenterol. 2014;28(4):573-83.

98. Swann JR, Want EJ, Geier FM, Spagou K, Wilson ID, Sidaway JE, et al. Systemic gut microbial modulation of bile acid metabolism in host tissue compartments. Proc Natl Acad Sci U S A. 2011;108 Suppl 1(Suppl 1):4523-30.

99. Shapiro H, Kolodziejczyk AA, Halstuch D, Elinav E. Bile acids in glucose metabolism in health and disease. J Exp Med. 2018;215(2):383-96 http:// doi:10.1084/jem.20171965.

100. Lazar V, Ditu LM, Pircalabioru GG, Picu A, Petcu L, Cucu N, et al. Gut microbiota, host organism, and diet Trialogue in diabetes and obesity. Front Nutr. 2019;6:21. https://doi.org/10.3389/fnut.2019.00021.

101. Sayin SI, Wahlström A, Felin J, Jäntti S, Marschall HU, Bamberg K, et al. Gut microbiota regulates bile acid metabolism by reducing the levels of taurobeta-muricholic acid, a naturally occurring FXR antagonist. Cell Metab. 2013; 17(2):225-35. https://doi.org/10.1016/j.cmet.2013.01.003.

102. Kuno T, Hirayama-Kurogi M, Ito S, Ohtsuki S. Reduction in hepatic secondary bile acids caused by short-term antibiotic-induced dysbiosis decreases mouse serum glucose and triglyceride levels. Sci Rep. 2018;8(1):1253. Published 2018 Jan 19. doi:https://doi.org/10.1038/s41598-018-19545-1

103. Agus A, Clément K, Sokol H. Gut microbiota-derived metabolites as central regulators in metabolic disorders. Gut. 2021;70(6):1174-82. https://doi.org/1 0.1136/gutjnl-2020-323071.

104. Nicholson JK, Holmes E, Kinross J, Burcelin R, Gibson G, Jia W, et al. Host-gut microbiota metabolic interactions. Science. 2012;336(6086):1262-7.

105. Chiang JY. Bile acid metabolism and signaling. Compr Physiol. 2013;3(3): 1191-212. https://doi.org/10.1002/cphy.c120023.

106. Cipriani S, Mencarelli A, Palladino G, Fiorucci S. FXR activation reverses insulin resistance and lipid abnormalities and protects against liver steatosis in Zucker (fa/fa) obese rats. J Lipid Res. 2010;51(4):771-84. https://doi.org/1 0.1194/jlr.M001602.

107. Hartmann P, Chen P, Wang HJ, Wang L, McCole DF, Brandl K, et al. Deficiency of intestinal mucin-2 ameliorates experimental alcoholic liver disease in mice. Hepatology. 2013;58(1):108-19.

108. Sohail MU, Althani A, Anwar H, Rizzi R, Marei HE. Role of the gastrointestinal tract microbiome in the pathophysiology of diabetes mellitus. J Diabetes Res. 2017;2017:9631435.

109. Everard A, Cani PD. Diabetes, obesity and gut microbiota. Best Pract Res Clin Gastroenterol. 2013;27(1):73-83.

110. Chopyk DM, Grakoui A. Contribution of the intestinal microbiome and gut barrier to hepatic disorders. Gastroenterology. 2020;159(3):849-63. https:// doi.org/10.1053/j.gastro.2020.04.077

111. Wang HB, Wang PY, Wang X, Wan YL, Liu YC. Butyrate enhances intestinal epithelial barrier function via up-regulation of tight junction protein
Claudin-1 transcription. Dig Dis Sci. 2012;57(12):3126-35. https://doi.org/10.1 007/s10620-012-2259-4.

112. Muccioli GG, Naslain D, Bäckhed F, Reigstad CS, Lambert DM, Delzenne NM, et al. The endocannabinoid system links gut microbiota to adipogenesis. Mol Syst Biol. 2010;6(1):392. https://doi.org/10.1038/msb.2010.46.

113. Cani PD, Osto M, Geurts L, Everard A. Involvement of gut microbiota in the development of low-grade inflammation and type 2 diabetes associated with obesity. Gut Microbes. 2012;3(4):279-88. https://doi.org/10.4161/gmic.19625.

114. Brun P, Castagliuolo I, Di Leo V, Buda A, Pinzani M, Palù G, et al. Increased intestinal permeability in obese mice: new evidence in the pathogenesis of nonalcoholic steatohepatitis. Am J Physiol Gastrointest Liver Physiol. 2007: 292(2):G518-25. https://doi.org/10.1152/ajpgi.00024.2006.

115. Dandona P, Aljada A, Bandyopadhyay A. Inflammation: the link between insulin resistance, obesity and diabetes. Trends Immunol. 2004;25(1):4-7. https://doi.org/10.1016/j.it.2003.10.013.

116. Reyes M, Quintanilla C, Burrows R, Blanco E, Cifuentes M, Gahagan S. Obesity is associated with acute inflammation in a sample of adolescents. Pediatr Diabetes. 2015;16(2):109-16. https://doi.org/10.1111/pedi.12129.

117. Delzenne NM, Cani PD, Everard A, Neyrinck AM, Bindels LB. Gut microorganisms as promising targets for the management of type 2 diabetes. Diabetologia. 2015;58(10):2206-17. https:/doi.org/10.1007/s00125-015-3712-7.

118. Hotamisligil GS, Shargill NS, Spiegelman BM. Adipose expression of tumor necrosis factor-alpha: direct role in obesity-linked insulin resistance. Science. 1993;259(5091):87-91.

119. Ley RE. Obesity and the human microbiome. Curr Opin Gastroenterol. 2010; 26(1):5-11.

120. Cani PD, Bibiloni R, Knauf C, Waget A, Neyrinck AM. Delzenne NM, et al changes in gut microbiota control metabolic endotoxemia-induced inflammation in high-fat diet-induced obesity and diabetes in mice. Diabetes. 2008:57(6):1470-81.

121. Cani PD, Neyrinck AM, Fava F, Knauf C, Burcelin RG, Tuohy KM, et al. Selective increases of bifidobacteria in gut microflora improve high-fat-dietinduced diabetes in mice through a mechanism associated with endotoxaemia. Diabetologia. 2007;50(11):2374-83. https://doi.org/10.1007/ s00125-007-0791-0.

122. Lindberg AA, Weintraub A, Zähringer U, Rietschel ET. Structure-activity relationships in lipopolysaccharides of Bacteroides fragilis. Rev Infect Dis. 1990; 12(Suppl 2):S133-41. https://doi.org/10.1093/clinids/12.Supplement_2.S133.

123. de Lartigue G. Barbier de la serre C, Espero E, Lee J, Raybould HE. Dietinduced obesity leads to the development of leptin resistance in vagal afferent neurons. Am J Physiol Endocrinol Metab. 2011;301(1):E187-95. https://doi.org/10.1152/ajpendo.00056.2011.

124. Raybould HE. Gut microbiota, epithelial function and derangements in obesity. J Physiol. 2012;590(3):441-6.

125. Cani PD, Amar J, Iglesias MA, Poggi M, Knauf C, Bastelica D, et al. Metabolic endotoxemia initiates obesity and insulin resistance. Diabetes. 2007;56(7): 1761-72. https://doi.org/10.2337/db06-1491.

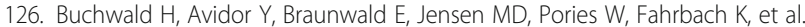
Bariatric surgery: a systematic review and meta-analysis. JAMA. 2004;292(14): 1724-37. https://doi.org/10.1001/jama.292.14.1724.

127. Bakker GJ, Nieuwdorp M. Fecal Microbiota Transplantation: Therapeutic Potential for a Multitude of Diseases beyond Clostridium difficile. Microbiol Spectr. 2017:5(4).

128. Lee P, Yacyshyn BR, Yacyshyn MB. Gut microbiota and obesity: an opportunity to alter obesity through faecal microbiota transplant (FMT). Diabetes Obes Metab. 2019;21(3):479-90. https://doi.org/10.1111/dom.13561.

129. Allegretti JR, Kassam Z, Mullish BH, Chiang A, Carrellas M, Hurtado J, et al. Effects of Fecal Microbiota Transplantation With Oral Capsules in Obese Patients. Clin Gastroenterol Hepatol. 2020;18(4):855-863.e2.

130. Smits LP, Kootte RS, Levin E, Prodan A, Fuentes S, Zoetendal EG, et al. Effect of vegan fecal microbiota transplantation on carnitine- and choline-derived trimethylamine-N-oxide production and vascular inflammation in patients with metabolic syndrome. J Am Heart Assoc. 2018;7(7):e008342.

\section{Publisher's Note}

Springer Nature remains neutral with regard to jurisdictional claims in published maps and institutional affiliations. 